\title{
Direito à imagem, agentes públicos e mídia: impactos sobre a proteção da imagem de suspeitos após a nova lei de abuso de autoridade
}

\author{
Right to image, public agents and media: impacts on protecting the image of suspects after the new \\ law of abuse of authority
}

Derechos de imagen, agentes públicos y medios de comunicación: impactos en la protección de la imagen de los sospechosos tras la nueva ley de abuso de autoridad

\section{Resumo}

O direito à imagem protege a representação física do corpo e dos traços característicos pelos quais a pessoa possa ser reconhecida. Suspeitos de cometer crimes sofriam violações por parte da mídia e de agentes públicos a esse direito. Essa violação influenciava a opinião pública, permitindo que cidadãos fossem julgados prematuramente, sem direito de defesa e presunção de inocência. As dificuldades de proteção ao direito à imagem apontavam para a necessidade de sua regulação pelo ordenamento jurídico, o que ocorreu recentemente com a vigência da Lei 13.869/2019, conhecida como nova lei de abuso de autoridade. Assim, o objetivo da pesquisa é investigar se o artigo 13 da Lei 13.869/2019 impactou na atuação de agentes públicos do Estado de Pernambuco e no discurso da mídia quanto a não violação ao direito à imagem. A metodologia utilizada na pesquisa será a análise de conteúdo das notícias sobre operações policiais, no combate ao crime de tráfico de drogas, no estado de Pernambuco divulgadas nos sites dos principais programas que apresentam ações policiais no estado, quais sejam: Por dentro com Cardinot (TV Jornal/SBT) e Balanço Geral PE (TV Clube/Rede Record), no período entre 2019 a 2020. Desse modo, espera-se que seja possível concluir se houve impacto na proteção da imagem dos suspeitos após a implementação da lei.

Palavras-chave: Direito à imagem; Violação; Mídia; Agente público; Lei 13.869/2019.

\begin{abstract}
The right to image protects the physical representation of the body and the characteristic features by which a person can be recognized. Suspects of committing crimes suffered violations of this right by the media and public officials. This violation influenced public opinion, allowing citizens to be judged prematurely, without the right to a defense and the presumption of innocence. The difficulties in protecting the right to image pointed to the need for its regulation by the legal system, which recently occurred with the enactment of Law 13,869/2019, known as the new law of abuse of authority. Thus, the objective of the research is to investigate whether article 13 of Law 13.869/2019 has impacted the performance of public agents of the State of Pernambuco and the media discourse regarding the nonviolation of the right to image. The methodology used in the research will be the content analysis of news about police operations, in the fight against the crime of drug trafficking in the state of Pernambuco, disseminated on the websites of the main programs that present police actions in the state, namely: Por dentro com Cardinot (TV Jornal/SBT) and Balanço Geral PE (TV Clube/Rede Record), in the period between 2019 and 2020. Thus, it is expected that it will be possible to conclude whether there was an impact on the protection of suspects' image after the implementation of the law.
\end{abstract}

Keywords: Right to image; Violation; Media; Public official; Law 13.869/2019.

\section{Resumen}

El derecho a la imagen protege la representación física del cuerpo y los rasgos característicos por los que se puede reconocer a la persona. Los sospechosos de cometer delitos sufrieron violaciones por parte de los medios de comunicación y agentes públicos a este derecho. Esta violación influyó en la opinión pública, permitiendo que los ciudadanos fueran juzgados de forma prematura, sin derecho a la defensa y presunción de inocencia. Las dificultades para proteger el derecho a la imagen señalaron la necesidad de su regulación por parte del ordenamiento jurídico, lo que sucedió recientemente con la promulgación de la Ley 13.869 / 2019, conocida como la nueva ley sobre abuso de autoridad. Así, el objetivo de la investigación es investigar si el artículo 13 de la Ley 13.869 / 2019 incidió en el desempeño de los agentes públicos en el estado de Pernambuco y en el discurso de los medios de comunicación sobre la no violación del derecho a la imagen. La metodología empleada en la investigación será el análisis de contenido de 
noticias sobre operaciones policiales en el combate al delito de narcotráfico en el estado de Pernambuco, publicadas en los sitios web de los principales programas que presentan acciones policiales en el estado, a saber: Inside with Cardinot (TV Jornal / SBT) y Balance General PE (TV Clube / Rede Record), en el período comprendido entre 2019 y 2020. Así, se espera que sea posible concluir si hubo impacto en la protección de los sospechosos 'imagen después de la aplicación de la ley.

Palabras clave: Derecho a la imagen; Violación; Medios de comunicación; Agente publico; Ley 13.869/2019.

\section{Introdução}

O questionamento que o projeto de pesquisa traz é: Quais os impactos do artigo 13 da Lei 13.869/2019 na atuação de agentes públicos do Estado de Pernambuco e no discurso da mídia quanto a não violação ao direito à imagem de suspeitos de cometer crimes?

A hipótese é que, diante da punição trazida pela lei, os agentes não estão violando o direito à imagem dos suspeitos de cometer crimes em casos de grande repercussão, sob a alegação que estão cumprindo a Lei 13.869/2019. Porém, nos crimes sem repercussão estão expondo a imagem dos suspeitos sob a alegação de que há interesse público envolvido.

Inicialmente, a ideia de imagem referia-se à reprodução de traços físicos da figura humana, não só a face, mas qualquer parte distinta de seu corpo. Porém, foi necessária uma ampliação e especificação da ideia de imagem, já que esta não engloba apenas o aspecto físico, mas também exteriorizações da personalidade do indivíduo em seu conceito social. Sendo assim, é bastante propício o conceito de Durval (1988, p. 105) que diz que: "Direito à imagem é a projeção da personalidade física (traços fisionômicos, corpo, atitudes, gestos, sorrisos, indumentárias, etc.) ou moral (aura, fama, reputação, etc.) do indivíduo no mundo exterior".

Os direitos da personalidade, dentre eles o direito à imagem, foram reconhecidos desde a Declaração do Homem e do Cidadão de 1789 e a partir daí, ganharam maior importância no ordenamento jurídico brasileiro com a promulgação da Constituição Federal de 1988.

$\mathrm{Na}$ Constituição de 1988, o direito à imagem está previsto em três incisos distintos do artigo $5^{\circ}$, quais sejam: incisos V, X e XXVIII, alínea "a”. No inciso V, encontra-se consagrada a proteção da "imagem-atributo" (denominação dada por Luiz Alberto David Araújo) que representa o conjunto de características por meio das quais a personalidade do indivíduo seria captada pela coletividade, no sentido do conceito social de que desfruta. No inciso $\mathrm{X}$, tem-se a proteção da imagem propriamente dita, a fisionomia e a forma plástica do sujeito. E, o inciso XXVIII, alínea "a" abarca a proteção da imagem no que concerne a proteção às participações individuais em obras coletivas e à reprodução da imagem e voz humanas, inclusive nas atividades desportivas (Franciulli Netto, 2004).

Desse modo, com a promulgação da Constituição Federal de 1988, o direito à imagem foi erigido ao status de direito autônomo. Quer dizer, o legislador conscientizou-se da importância do direito à imagem e dotou-o de proteção legal, independentemente da ofensa ou não de outro direito da personalidade.

O atual Código Civil, na esteira da Constituição Federal, disciplina, em seu artigo 20, a proteção específica do direito em análise ao ressalvar que a divulgação da imagem só poderá ser feita com o consentimento de seu titular, prevendo, por outro lado, a possibilidade de indenização quando violado.

A divulgação de matéria ao arrepio da preservação do nome, de informações pessoais e da imagem de um suspeito de cometer crime, por exemplo, sem que este tenha sequer autorizado, maculando sua boa fama, influindo no conceito de sua pessoa junto às pessoas de seu convívio, é sem dúvida, ato que deve gerar imediata responsabilidade civil e/ou penal, conforme previsão da Constituição Federal (artigo $5^{\circ}$, incisos V, X e XXVIII) e do Código Civil (artigo 20). Contudo, a exposição da imagem e da vida íntima traz consequências que nenhum tipo de indenização pode reparar.

Ainda assim, atualmente, o direito à imagem é, dentre os direitos da personalidade, o mais relativizado e/ou violado, seja porque é aquele que mais possibilita exploração pecuniária ou porque sua violação pode vir a ser "necessária" em alguns 
casos específicos de interesse público. Por isso, diariamente, são vistas notícias de pessoas que foram expostas pela mídia de forma indevida, tendo assim, seu direito à imagem violado.

A experiência tem demonstrado que quando se depara com um suspeito, frente às câmaras de televisão, muitas vezes querendo esconder o rosto, ou mesmo fugindo da insistência do repórter, tem, a grande maioria da população, a sensação de que o repórter está agindo de forma correta e que não existe direito à imagem para aquele suspeito, o que não é verdade.

O artigo 4", alínea "b" da Lei 4.898 de 1965 que regulava o direito de representação e o processo de responsabilidade administrativa, civil e penal, nos casos de abuso de autoridade, dizia que constitui abuso de autoridade "submeter pessoa sob sua guarda ou custódia a vexame ou a constrangimento não autorizado em lei". Porém, como não havia previsão expressa de proteção ao direito à imagem nem qualquer punição a sua violação na referida lei, ocorriam constantes abusos e os agentes públicos, via de regra, não recebiam qualquer punição.

Ocorre que em 3 de janeiro de 2020, entrou em vigor a Lei 13.869/2019, popularmente conhecida como lei de abuso de autoridade, que regou a Lei 4.898 de 1965 e, em seu artigo 13, passou expressamente a proibir, sob pena de detenção, a violação ao direito à imagem de suspeitos de cometer crime por parte de agentes públicos. O que indica que esse cenário de violação ao direito à imagem de suspeitos pode mudar.

De acordo com o artigo 13 da Lei 13.869/2019, é crime de abuso de autoridade constranger o preso ou o detento, mediante violência, grave ameaça ou redução de sua capacidade de resistência, a: I - exibir-se ou ter seu corpo ou parte dele exibido à curiosidade pública; II - submeter-se a situação vexatória ou a constrangimento não autorizado em lei; III - produzir prova contra si mesmo ou contra terceiro. A pena prevista é de detenção, de 1 (um) a 4 (quatro) anos, e multa, sem prejuízo da pena cominada à violência.

Para que essas condutas sejam configuradas como crime de abuso de autoridade, a lei, em seu artigo $1^{\circ}$, parágrafo $1^{\circ}$, exige que o agente público as pratique com a finalidade de prejudicar outrem, beneficiar a si mesmo ou a terceiro, ou, ainda, por mero capricho ou satisfação pessoal. Portanto, caso não fique demonstrado que o agente público agiu com estas finalidades específicas, o fato não será considerado como crime de abuso de autoridade.

Por fim, vale ressaltar que, a Lei 13.869/2019, em seu artigo $2^{\circ}$, deixa claro que quem pode ser enquadrado como autor de crime de abuso de autoridade é qualquer agente público, servidor ou não, da administração direta, indireta ou fundacional de qualquer dos Poderes da União, dos Estados, do Distrito Federal, dos Municípios e de Território, compreendendo, mas não se limitando a: I - servidores públicos e militares ou pessoas a eles equiparadas; II - membros do Poder Legislativo; III - membros do Poder Executivo; IV - membros do Poder Judiciário; V - membros do Ministério Público; VI - membros dos tribunais ou conselhos de contas. Também é sujeito ativo do crime de abuso de autoridade, para os efeitos da referida lei, todo aquele que exerce, ainda que transitoriamente ou sem remuneração, por eleição, nomeação, designação, contratação ou qualquer outra forma de investidura ou vínculo, mandato, cargo, emprego ou função em órgão ou entidade pública.

E, diante desse novo quadro se desenha, surge a necessidade de se investigar os impactos do artigo 13 da Lei 13.869/2019 na atuação de agentes públicos do Estado de Pernambuco, no Brasil, bem como no discurso da mídia quanto a não violação ao direito à imagem.

\section{Metodologia}

A fim de examinar mais a fundo os assuntos abarcados pelo tema, pretende-se desenvolver uma análise de conteúdo dos vídeos das notícias sobre crimes disponibilizados nos sites dos programas "Por dentro com Cardinot" (TV Jornal/SBT) e "Balanço Geral PE" (TV Clube/Rede Record) no período de 2019 a 2020. Os sites desses programas televisivos disponibilizam os vídeos das matérias que foram ao ar desde o ano de 2018 até os dias atuais. 
A escolha dos referidos programas se deu em função de serem estes os principais meios televisivos e digitais de divulgação de operações policiais no Estado de Pernambuco. E, a delimitação temporal nos permite estabelecer uma comparação entre as ações dos agentes públicos e o discurso da mídia, antes e depois da vigência da Lei 13.869/2019 (nova lei de abuso de autoridade).

Diante da extensa quantidade de matérias relacionadas a prática de crimes exibidas nos programas televisivos mencionados, delimitou-se que serão analisados apenas os casos envolvendo o crime de tráfico de drogas, por liderar o ranking dos delitos mais comuns entre os detentos do país, considerando as pessoas condenadas e os presos provisórios, segundo o Levantamento Nacional de Informações Penitenciárias (Infopen) de 2019, divulgado pelo Ministério da Justiça e Segurança Pública do Governo Federal. O estudo constatou um crescimento de 3,89\% da população carcerária, chegando a 773.151 pessoas em junho de 2019. E, nesse contingente há 163,2 mil casos de crimes de tráfico de drogas. Ainda de acordo com o mencionado levantamento, no Estado de Pernambuco o número de pessoas presas é maior que 33 mil.

Seguindo o procedimento metodológico, cumpre destacar que a análise de conteúdo compreende um conjunto de técnicas de pesquisa que busca avaliação qualitativa do sentido de um documento ou discurso. A análise de conteúdo é uma técnica de exame das comunicações, que irá permitir averiguar o que foi dito nas matérias televisivas e digitais, a partir da classificação das informações em temas ou categorias que auxiliam na compreensão do que está por trás dos discursos dos agentes públicos e dos repórteres.

Partindo dessa técnica, pretende-se seguir as seguintes etapas: A primeira etapa visa sistematizar as ideias apresentadas pelo referencial teórico e estabelecer indicadores para a interpretação das informações coletadas. A segunda etapa consiste na definição de regras de contagem e a classificação e reunião das informações. E a terceira etapa compreende o tratamento dos resultados, consiste em captar os conteúdos manifestos e latentes contidos em todo o material coletado (Bardin, 2002).

A partir dessa investigação científica será possível concluir se houve impacto na proteção ao direito à imagem após a implementação da Lei 13.869/2019, seja na atuação dos agentes públicos seja no discurso da mídia.

\section{Resultados e Discussão}

Conforme entendimento de Bobbio, "o problema fundamental em relação aos direitos do homem, hoje, não é tanto de justificá-los, mas o de protegê-los. Trata-se de um problema não filosófico, mas político" (Bobbio, 2004, p. 23). No entanto, a Sociedade não vê o criminoso como sujeito de direitos humanos. Segundo Lindgren Alves, "o criminoso comum é 'por natureza' outro, um ser distinto ou outra coisa, que se diferencia, por sua atividade transgressora, da espécie a que pertencemos nós, cidadãos honestos e seres humanos verdadeiros" (Alves, 2005, p. 4). O que evidencia que, sendo o outro diferente de nós, sua punição não seria nada mais que uma retribuição, uma tentativa de retirar "as impurezas" da sociedade.

O autor segue informando que“ inteligível pela ótica, mas inaceitável na esfera do Direito e da Justiça, essa postura diante da alteridade é ainda mais nefasta e mais tragicamente consequente quando baseada em outros critérios diferenciadores, algumas vezes 'legais', que nada têm a ver com a criminalidade " (Alves, 2005, p. 4).

Assim sendo, para analisar os impactos do artigo 13 da Lei 13.869/2019 na atuação de agentes públicos do Estado de Pernambuco e o discurso da mídia quanto a não violação ao direito à imagem de suspeitos de cometer crime, inicialmente será necessário conhecer o processo identitário de construção da suspeição dos indivíduos acusados de cometer crime, bem como conhecer o discurso não apenas como produção de palavras e textos, mas como instrumento de construção do mundo e da realidade, um exercício do poder.

Considerando que a violação ao direito à imagem de suspeitos de cometer crimes, não se trata apenas de exibir um conjunto de imagens, mas revela a produção discursiva do processo de identidade da pessoa suspeita de cometer crime. 
Acredita-se, conforme o entendimento de Stuart Hall, em sua obra Identidade cultural na pós-modernidade, que a construção da identidade é formada e transformada continuamente; sofre influência das formas como o indivíduo é representado ou interpretado nos e pelos diferentes sistemas culturais de que toma parte (Hall, 2006).

Uma vez que o presente trabalho se propõe a conhecer as narrativas televisivas e a ação dos agentes públicos que constroem as identidades dos suspeitos de cometer crimes, as ideias de Stuart Hall são essenciais, pois entendem as identidades como construídas no interior do jogo do poder e da exclusão:

"Utilizo o termo 'identidade' para significar o ponto de encontro, o ponto de sutura, entre, por um lado, os discursos e as práticas que tentam nos 'interpelar', nos falar ou nos convocar para que assumamos nossos lugares como os sujeitos sociais de discursos particulares e, por outro lado, os processos que produzem subjetividades, que nos constroem como sujeitos aos quais se pode 'falar'. As identidades são, pois, pontos de apego temporário às posiçõesde-sujeito que as práticas discursivas constroem para nós. Elas são o resultado de uma bem sucedida articulação ou 'fixação' do sujeito ao fluxo do discurso [...] Isto é, as identidades são as posições que o sujeito é obrigado a assumir, embora 'sabendo', sempre, que elas são representações [...] (Hall, 2000, p. 111-112)".

Hall sugere ampliar o foco de observação, pensar a identidade como uma construção, utilizar uma abordagem discursiva, ou seja, um processo de compreensão, de intelecção do mundo através da capacidade simbólica de interação com o outro, mediado pela palavra enquanto signo pleno de sentido histórico e social.

Nesse sentido, a violação ao direito à imagem, aflora a estigmatização de pessoas, grupos, comportamentos e situações ao lado da consequente criminalização dos mesmos com o auxílio da mídia, que embora desenvolva uma função importante para a efetivação da democracia, frequentemente, por meio do discurso, exerce o papel de incitadora da violência e da manutenção do poder. Desse modo, a Lei 13.869/2019 surge como uma tentativa de coibir a exibição de suspeitos de cometer crime - pessoas estigmatizadas - desprovida de interesse público, onde se visa, tão somente, entregar o indivíduo a sanha popular de saber quem ele é e o que fez.

Para tanto, pretende-se aprofundar os estudos sobre o discurso com base nas ideias de Maingueneau, uma vez que este autor entende o discurso como forma de ação produzida dentro de um determinado contexto. Para o autor, "falar é uma forma de ação sobre o outro e não apenas uma representação do mundo". O que significa que o discurso, enquanto ato de linguagem, interfere na realidade, ocasionando mudanças nos destinatários. Além disso, o autor acredita que não se pode atribuir um significado fora do contexto, uma vez que "o "mesmo" enunciado em dois lugares distintos corresponde a dois discursos distintos" (Maingueneau, 2004, p. 53 e 54).

O que significa que quem tem um discurso convincente pode utilizá-lo para manipular ou dominar pessoas, direcionar a história, por isso o discurso passa a ser cobiçado, temido por seu simbolismo, sua força (Sousa, 2010).

Segundo Foucault (2004), o discurso, enquanto instituição de poder, atua através da subjetividade presente nos meios de comunicação social, utiliza-se de uma linguagem que faz o destinatário defender o ponto de vista do seu opressor, isto é, o discurso torna-se uma forma de manipulação e exclusão.

$\mathrm{O}$ referido autor deu à palavra poder uma conotação mais ampla e dinâmica, estando muito além de sua origem etimológica ou definição. O poder, para Foucault, não é uma manifestação isolada, mas um conjunto de um todo complexo que se desenvolve em todas as instituições sociais e exerce controle sobre o corpo, os gestos, as atitudes, os comportamentos e hábitos.

Assim sendo, investigar os impactos da Lei 13.869/2019 na atuação dos agentes públicos, bem como no discurso da mídia sobre a violação ao direito à imagem de suspeitos de cometer crimes, torna-se uma maneira de se contrapor a relação de dominação sobre aqueles que não se enquadram em determinados estereótipos impostos pela sociedade. 
Portanto, busca-se capturar a recorrência dos termos e expressões utilizados nos processos de suspeição do indivíduo frente a sociedade, bem como compreender quais são as estratégias que estão sendo usadas para a exposição dos atos e fatos criminosos sem a indicação do nome e da imagem das pessoas. Além disso, espera-se encontrar o cenário atual do uso da imagem em programas policiais, assim como oferecer contribuições que permitam desnaturalizar a violação ao direito à imagem de suspeitos de cometer crimes e desvendar a prática discursiva utilizada nesse cenário.

\section{Considerações Finais}

A motivação para realizar essa pesquisa deve-se ao fato de o direito à imagem ser um campo fértil de investigação, uma vez que a imagem é absorvida e transmitida com extrema rapidez e facilidade pela mídia, tornando-se um bem jurídico facilmente violável. E, nos casos de suspeitos de cometer crime, é apresentada de maneira fragmentada e descontextualizada sendo necessário ampliar os estudos relativos ao conteúdo do direito à imagem e aos meios para a sua proteção.

Ao estampar o resto de um sujeito, sem seu consentimento, além de você dar mais crueldade ao fato, extrapola o sujeito através da família, vizinhos, etc. Depois da exibição da imagem, se a acusação não for confirmada, como o sujeito volta para casa?

Além disso, a relevância de se estudar os impactos do artigo 13 da Lei 13.869/2019 para coibir a exposição da imagem por parte dos agentes públicos, deve-se ao fato de tentar garantir que a partir dos holofotes das câmeras, a dignidade do ser humano tenha maior importância e a imagem das pessoas suspeitas de cometer crimes deixe de ser matéria-prima da diversão, bem como instrumento de manutenção de poder do Estado.

A relevância do tema deve-se ainda a uma tentativa de analisar se agentes públicos continuam a contribuir, após a publicação da referida lei, para que a mídia exiba programas nos quais se espetaculariza a violência e toleram-se a violação ao direito à imagem dos indivíduos suspeitos de cometer crime em troca de audiência e lucro. O que torna a vida privada em espetáculo público.

Por fim, ressalto que o tema do presente artigo, por ser muito inquietante e atual, nos leva a diversos questionamentos, tais como: Quantas punições foram aplicadas aos agentes públicos por violação ao direito à imagem de suspeitos de cometer crime?; Os agentes públicos receberam alguma formação sobre os cuidados a serem tomados para não violar ao direito à imagem de suspeitos?; Qual o perfil socioeconômico e racial dos suspeitos de cometer crime que tiveram sua imagem violada?; Houve denúncia de suspeitos de agentes que violaram a sua imagem? E esses são alguns dos caminhos possíveis para debates e pesquisas futuros sobre a temática que merecem nossa atenção.

\section{Referências}

Affonso, F. J. M. (2021). O direito à imagem na era das deep fakes. Revista RBD Civil. 27(1). https://rbdcivil.emnuvens.com.br/rbdc/article/view/438.

Alves, J. A. L. (2005). Os direitos humanos na pós-modernidade. Perspectiva.

Bardin, L. (2002). Análise de conteúdo. Edições 70.

Brasil (1988). Constituição da República Federativa do Brasil de 1988. http://www.planalto.gov.br/ccivil_03/constituicao/constituicao.htm.

Brasil (2002). Código Civil - Lei no 10.406 de 10 de janeiro de 2002. http://www.planalto.gov.br/ccivil_03/leis/2002/110406compilada.htm.

Brasil (2019). Lei $n^{o} 13.869$ de 5 de setembro de 2019. http://www.planalto.gov.br/ccivil_03/_ato2019-2022/2019/lei/L13869.htm.

Brasil (2020). Levantamento Nacional de Informações Penitenciárias (Infopen) do ano de 2019. Ministério da Justiça e Segurança Pública. http://antigo.depen.gov.br/DEPEN/depen/sisdepen/infopen.

Bobbio, N. (2004). A era dos direitos. Campus.

Castro, J. R. de, \& Castro, J. R. de (2020). Direito Humano e Fundamental do acesso à justiça: análise do jus postulandi e a indispensabilidade do advogado sob a perspectiva dos direitos da personalidade. Research, Society and Development, 9(12), e36191211196, 10.33448/rsd-v9i12.11196. https://rsdjournal.org/index.php/rsd/article/view/11196. 
Research, Society and Development, v. 10, n. 16, e181101623321, 2021

(CC BY 4.0) | ISSN 2525-3409 | DOI: http://dx.doi.org/10.33448/rsd-v10i16.23321

Coutinho, L. M. \& Quartiero, E. M. (2020). Cultura, mídias e identidades na Pós-modernidade. Florianópolis: Perspectiva, 27(1), 47-68, http://www.perspectiva.ufsc.br.

Debord, G. (1997). A sociedade do espetáculo. Contraponto.

Durval, H. (1988). Direito à imagem. Editora Saraiva.

Foucault, M. (2004). A ordem do discurso. Edições Loyola.

Franciulli Netto, D. (2020). A Proteção ao Direito à Imagem e a Constituição Federal. Informativo Jurídico da Biblioteca Ministro Oscar Saraiva, 16(1), 1-74, https://webcache.googleusercontent.com/search?q=cache:fETa50r9VQEJ:https://ww2.stj.jus.br/publicacaoinstitucional/index.php/informativo/article/downloa $\mathrm{d} / 442 / 400+\& \mathrm{~cd}=1 \& \mathrm{hl}=\mathrm{pt}-\mathrm{BR} \& \mathrm{ct}=\mathrm{clnk} \& \mathrm{gl}=\mathrm{br}$.

Hall, S. (2006). Identidade cultural na pós-modernidade. DP\&A.

Hall, S. (2000). Quem precisa da identidade? In:, T.T. (org), Identidade e diferença: a perspectiva dos estudos culturais, 103-133. Vozes.

Lima, R. B. (2020). Nova lei de abuso de autoridade. Juspodivm.

Lima, V. A. de (2012). Liberdade de expressão x liberdade de imprensa: direito à comunicação e a democracia. (2a ed.), Publisher Brasil.

Lindgren Alves, J. A. (2005). Os direitos humanos na pós-modernidade. Perspectiva.

Lobo, E. da C., Lima, N. A. de (2020). Limites ao Direito Constitucional à imagem sob a ótica da veiculação de fotografias em matérias jornalísticas policiais. Nova Hileia/Revista Eletrônica de Direito Ambiental da Amazônia. 7(1), 1-20, http://periodicos.uea.edu.br/index.php/novahileia/article/view/1696.

Maingueneau, D. (2004). Análise de textos de comunicação. Tradução Cecília P. de Souza e Silva. Décio Rocha. (3a ed.), Cortez.

Santos, B. de S., \& Chaui, M. (2013). Direitos Humanos. Democracia e Desenvolvimento. Cortez.

Sarlet, I. W. (2010). A Eficácia dos Direitos Fundamentais: uma teoria geral dos direitos fundamentais na perspectiva constitucional. Livraria do Advogado.

Sousa, S. A. de (2020). Discurso, autor e sujeito dentro da obra A Ordem do Discurso de Michel Foucault: uma análise metadiscursiva. https://www.ufjf.br/darandina/files/2010/01/Simone-Aparecida-de-Sousa.pdf. 